Primljen / Received: 30.7.2016. Ispravljen / Corrected: 19.2.2017.

Prihvaćen / Accepted: 28.2.2017. Dostupno online / Available online: 10.3.2018.

\section{Periods and vibration modes for common RC frame structures}

Authors:

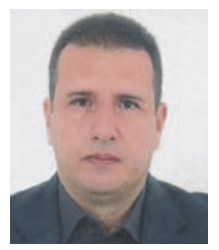

Mohamed Chennit, MCE

University of Science and Technology Houari Boumediene - Algeria

Faculty of Civil Engineering

chennmoh@gmail.com

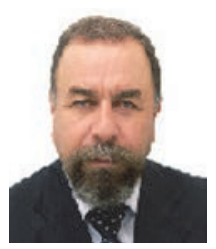

Prof. Djilali Benouar, PhD. CE

University of Science and Technology Houari Boumediene - Algeria

Faculty of Civil Engineering

dbenouar@gmail.com

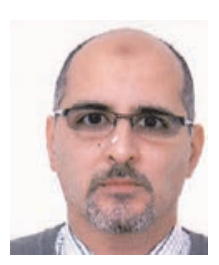

Assoc.Prof. Abdelkrim Bourzam, PhD. CE University of Science and Technology Houari Boumediene - Algeria

Faculty of Civil Engineering

bourzam@gmail.com
Scientific Paper - Preliminary report

\section{Mohamed Chennit, Djilali Benouar, Abdelkrim Bourzam}

\section{Periods and vibration modes for common RC frame structures}

A theoretical method allowing determination of vibration modes for RC frame structures with identical floors, or with either the first or the last floor differing from other floors, is proposed in the paper. As a result of the research, all natural vibration modes for buildings with two to ten identical storeys are presented in a table. These results can be extended to include a greater number of floors (more than ten). A mathematical method for determining characteristic polynomial coefficients of a specific tridiagonal matrix is also proposed.

Key words:

structure, natural period, mode shapes, vibration modes, eigenvectors, eigenvalue

Prethodno priopćenje

Mohamed Chennit, Djilali Benouar, Abdelkrim Bourzam

\section{Periodi i oblici titranja uobičajenih okvirnih AB gradevina}

U ovom se radu predlože teoretska metoda koja omogućuje određivanje oblika titranja okvirnih AB građevina s identičnim katovima ili s prvim ili zadnjim katom različitim od ostalih. Kao rezultat istraživanja, tablično su prikazani svi prirodni oblici titranja građevina s dva do deset identičnih katova. Ti se rezultati mogu proširiti na veći broj katova (više od deset). Predlaže se i matematička metoda za određivanje karakterističnih koeficijenata polinoma za posebnu trodijagonalnu matricu.

Ključne riječi:

gradevina, prirodni period, vlastiti oblici, oblici titranja, vlastiti vektori, vlastita vrijednost

Vorherige Mitteilung

Mohamed Chennit, Djilali Benouar, Abdelkrim Bourzam

\section{Schwingungszeiträume und -formen üblicher Stahlbetongebäude}

In dieser Abhandlung wird eine theoretische Methode vorgeschlagen, welche die Bestimmung der Schwingungsformen von allgemeinen Stahlbetongebäuden mit identischen Stockwerken oder mit einem unterschiedlichen ersten oder letzten Stockwerk ermöglicht. Als Ergebnis der Untersuchung sind alle natürlichen Formen der Gebäudeschwingung mit zwei bis zehn identischen Stockwerken tabellarisch dargestellt. Diese Ergebnisse können auf eine größere Anzahl an Stockwerken (mehr als zehn) erweitert werden. Vorgeschlagen wird auch eine mathematische Methode zur Bestimmung der charakteristischen Polynomkoeffizienten für eine spezielle dreidimensionale Matrix.

Gebäude, natürlicher Zeitraum, eigene Formen, Schwingungsformen, eigene Vektoren, eigener Wert 


\section{Introduction}

The seismic design of buildings requires either theoretical or experimental determination of natural modes of vibration. For this purpose, several methods have been developed based on the use of experimental data leading to the development of empirical formulas of the fundamental period. This is, generally, a function of a building height or a number of floors. Several authors including those cited in [1-4] have studied these experimental methods.

Theoretical methods have also been developed by several authors, as shown in [5-7]. The diagonalisation of Jacobi method was developed and deepened by Hochstenbach [8]. The power method outlined by Golub and Van Loan [9] and the Arnoldi method [10] were deepened by Saad [11]. Davidson's method [12] has been investigated by several authors such as Crouzeix [13] and Morgan [14]. Verderam [15] and Oliveira [16] have compared the results obtained by experimental measurements to those derived by numerical calculations based on analytical methods. The determination of all natural modes of vibration has attracted the interest of many authors including Tong [17].

The aim of the method presented in this research is to theoretically determine all natural modes of vibration. This method is based on the determination of the polynomial, denoted $P$, derived from the determinant $P=\left\|[K]-\omega^{2}[\mathrm{M}]\right\|$ where $[K],[M]$ and $\omega$ represent the stiffness, the mass matrices and the angular frequency of the structure, respectively. The roots of this polynomial are angular frequencies of the structure.

During the polynomial developments, corresponding to buildings with " $n$ " identical storeys, a process allowing determination of the coefficients of these polynomials is highlighted. Once these polynomials are determined, their resolutions are performed using numerical methods for calculating the roots of a polynomial of degree $n$. These roots are used to deduce pulsations of the structure. Thereafter, eigenvectors are calculated for each value of natural pulsation. Thus, a database containing all natural modes of vibration of the 2 to 10 storey buildings is established (with the possibility of extending the number of storeys).

Two additional cases, considered as being the most common in practice, have been studied in order to extend the field of application of this method. These cases represent buildings having either the first or the last storey different from other storeys.

The objective of this research work is to propose a simple and effective method for the determination of all natural modes of vibration that are necessary for seismic design of buildings. Additionally, all vibration modes of buildings having two to ten identical storeys are summarized in the proposed table. These results can be extended to a higher number of storeys (more than ten). The investigation of this table enables easy determination of all natural modes without repetition of calculations related to this type of buildings.

\section{Building with " $n$ " identical storeys}

\subsection{Modelling}

Usually and quite commonly in building dynamic analysis, the mass of any storey is concentrated in its corresponding floor as shown in Figure 1.

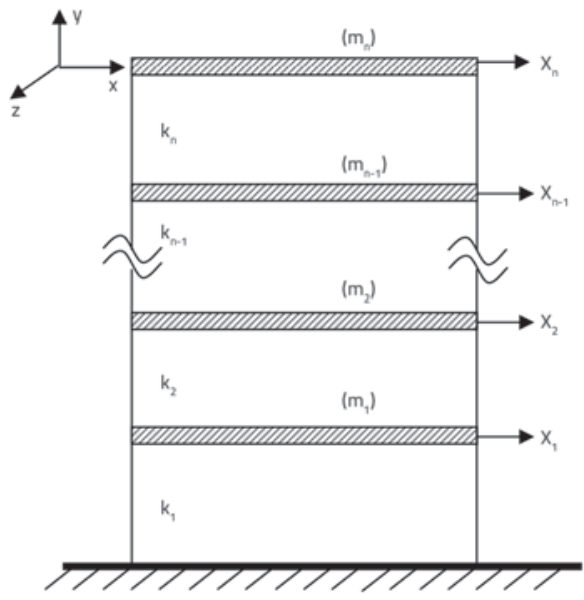

Figure 1. Building modelling

The stiffness and the mass of each storey are marked as $\mathrm{k}_{\mathrm{i}}$ and $\mathrm{m}_{\mathrm{i}}$ respectively. $x_{i}$ is the displacement of each floor. It is assumed that:

- Floors are considered non-deformable and columns fixed at floors.

- Masses are concentrated at floor storeys.

- Each floor has a horizontal displacement $x_{i}$ in the direction $\left(x x^{\prime}\right)$, and rotation is restrained.

The stiffness matrix for $\mathrm{n}$ identical storeys is expressed:

$[\mathrm{K}]=\mathrm{k}[\overline{\mathrm{K}}]$

where, $\mathrm{k}$ is the stiffness of each storey in horizontal direction and the matrix $[\bar{K}]$ is equal to:

$[\bar{K}]=\left[\begin{array}{ccccc}2 & -1 & 0 & 0 & 0 \\ -1 & 2 & \ldots . & 0 & 0 \\ 0 & \ldots . & \ldots . & \ldots & 0 \\ 0 & 0 & \ldots . & 2 & -1 \\ 0 & 0 & 0 & -1 & 1\end{array}\right]$

\subsection{Angular frequencies}

The matrix order $[\bar{K}]$ depends on the number of Degrees Of Freedom (DOF). This matrix is a specific tridiagonal matrix. This type of matrix has been studied by several authors such as Buchholzer [18], Jia [19] and Hou-Bia [20]. The mass matrix [M] is expressed by Eq. (3) as follows:

$$
[\mathrm{M}]=\mathrm{m}[\mathrm{I}]
$$


where $\mathrm{m}$ is the mass of each storey and [I] the identity matrix, in which the order depends on the number of DOF.

Angular frequencies of vibration are obtained by solving Eq. (4):

$\left\|[K]-\omega^{2}[M]\right\|=0$

By substituting the matrices $[\mathrm{K}]$ and $[\mathrm{M}]$ with their respective expressions, Eq. (4) becomes:

$\left\|[\bar{K}]-\frac{\omega^{2}}{\omega_{0}^{2}}[l]\right\|=0$ where $\omega_{0}^{2}=\frac{k}{m}$

Eq. (5) can also be expressed by:

$\|[\bar{K}]-\alpha[I]\|=0$ where $\alpha=\frac{\omega^{2}}{\omega_{0}^{2}}$

The polynomial $P_{n}(\alpha)=\|[\bar{K}]-\alpha[I]\|$ allows determination of eigenfrequencies and eigenvectors for any building of $n$ identical storeys. This polynomial is independent of the values of stiffness $k$ and masses $m$.

Once the roots of the polynomial $P_{n}(\alpha)$ are determined, angular frequencies can be deduced from the following relationship:

$\omega^{2}=\alpha \cdot \omega_{0}^{2}$ where $\omega_{0}^{2}=\frac{k}{m}$

The polynomial for RC frame buildings of different number of storeys has been developed as follows:

- Zero storey (virtual building): $P_{0}(\alpha)=1\left(a_{11}=1\right.$, Table 1.)

- One storey: $\quad P_{1}(\alpha)=1-\alpha$

- Two identical storeys: $P_{2}(\alpha)=1-3 \alpha+\alpha^{2}$

- Three identical storeys: $P_{3}(\alpha)=1-6 \alpha+5 \alpha^{2}-\alpha^{3}$

- Four identical storeys $P_{4}(\alpha)=1-10 \alpha+15 \alpha^{2}-7 \alpha^{3}+\alpha^{4}$

- Five identical storeys: $P_{5}(\alpha)=1-15 \alpha+35 \alpha^{2}-28 \alpha^{3}+9 \alpha^{4}-\alpha^{5}$.
Based on these developments, a process aimed at determining all coefficients of the polynomial $P_{n}(\alpha)$ has been found and highlighted. This process is outlined in Table 1. Starting the matrix from Table 1 by $a_{11}=1$ is essential for finding correct polynomial coefficients according to the algorithm logic. The same explanation is applicable to buildings in which the first or last storey is different from other storeys (see Tables 4 and 5). Each coefficient is determined by the summation of all coefficients of the column located on the left and above the considered coefficient and the value of the coefficient located just above (from Table 1 coefficient $15=1+3+6+5$ ). The first polynomial coefficient is 1 .

All coefficients of any polynomial corresponding to $n$ storeys building ( $\mathrm{DDOF}$ ) can be determined starting from a single degree of freedom which corresponds to the polynomial $P_{1}(\alpha)=1-\alpha$.It is noted that the polynomial has alternated signs. Polynomial coefficients are expressed as follows:

$a_{i j}= \begin{cases}0 & j>i \\ 1 & j=1 ; i=1, \ldots, n \\ a_{(i-1) j}+\sum_{k=1}^{i-1} a_{k(j-1)} \quad 2 \leq j \leq i\end{cases}$

It is noted that the Number Of Storey (NOS) is equal to (i-1): NOS $=\mathrm{i}-1$. And the polynomial of a building of $n$ storeys is:

$P_{n}(\alpha)=\sum_{k=0}^{n}(-1)^{k} a_{(n+1)(k+1)} \alpha^{k}$

Once these polynomials are expressed, their roots $\alpha_{i}$ are isolated by using the algorithm developed by Akritas $\&$ al [21] and the bisection method allows approaching these roots.

Several methods for determining the characteristic polynomials have been developed. Among these methods, the La Budde one is the closest to the proposed method.

Table 1. Polynomial coefficients $P_{n}(\alpha)$ for RC frame buildings of identical storeys

\begin{tabular}{|c|c|c|c|c|c|c|c|c|c|c|c|}
\hline $\begin{array}{l}\text { Number } \\
\text { of storevs }\end{array}$ & & & $\mathrm{ng}$ of $\mathrm{t}$ & nominal & e & & & & & & \\
\hline 0 & $a_{11}=1$ & & & & & & & & & & \\
\hline 1 & $a_{21}=1$ & 1 & & & & & & & & & \\
\hline 2 & 1 & 3 & 1 & & & & & & & & \\
\hline 3 & 1 & 6 & 5 & 1 & & & & & & & \\
\hline 4 & 1 & 10 & 15 & 7 & 1 & & & & & & \\
\hline 5 & 1 & 15 & 35 & 28 & 9 & 1 & & & & & \\
\hline 6 & 1 & 21 & 70 & 84 & 45 & 11 & 1 & & & & \\
\hline 7 & 1 & 28 & 126 & 210 & 165 & 66 & 13 & 1 & & & \\
\hline 8 & 1 & 36 & 210 & 462 & 495 & 286 & 91 & 15 & 1 & & \\
\hline 9 & 1 & 45 & 330 & 924 & 1287 & 1001 & 455 & 120 & 17 & 1 & \\
\hline 10 & 1 & 55 & 495 & 1716 & 3003 & 3003 & 1820 & 680 & 153 & 19 & 1 \\
\hline
\end{tabular}


La Budde's method consists of two stages: In the first one, $[A]$ is reduced to the upper Hessenberg form $[\mathrm{H}]$ with orthogonal similarity transformations and, in the second stage, the characteristic polynomial of $[\mathrm{H}]$ is computed using recurrence of sub-matrices. Knowing that $[\mathrm{H}]$ and $[\mathrm{A}]$ are similar, they have the same characteristic polynomials. If $[A]$ is symmetric then $[\mathrm{H}]$ is a symmetric tridiagonal matrix and the La Budde's method simplifies to the Sturm sequence method [22]. This case corresponds to the study presented in this paper. La Budde's algorithm for calculating coefficients of the characteristic polynomial is presented in the following development.

$$
[A]=\left[\begin{array}{ccccc}
a_{1} & b_{2} & 0 & 0 & 0 \\
b_{2} & a_{2} & \ldots . & 0 & 0 \\
0 & \ldots . & \ldots . . & \ldots & 0 \\
0 & 0 & \ldots & a_{n-1} & b_{n} \\
0 & 0 & 0 & b_{n} & a_{n}
\end{array}\right]
$$

where $[A]$ is a symmetric tridiagonal matrix $(n \times n)$.

In the process of computing the characteristic polynomial $P_{i}(\lambda)=$ $\operatorname{det}\left(\lambda I-T_{i}\right)$, the Sturm sequence method computes characteristic polynomials $P_{i}(\lambda)=\operatorname{det}\left(\lambda I-T_{i}\right)$ of all leading principal submatrices $T_{i}$ of order $i$, where $P_{n}(\lambda)=P(\lambda)$. The recursion for computing $P(\lambda)$ is presented in Eq. (11) [22, 9]:

$P_{n}(\lambda)=\left\{\begin{array}{l}P_{0}(\lambda)=1, \quad P_{1}(\lambda)=1-\alpha \\ P_{i}(\lambda)=\left(\lambda-a_{i}\right) P_{i-1}(\lambda)-b_{i}^{2} P_{i-2}(\lambda) \quad 2 \leq i \leq n\end{array}\right.$

In order to recover individual coefficients of $P(\lambda)$ from the recursion of Eq.(11), the polynomial coefficients are identified by Eq. $(12),[22,9]$ :

$P(\lambda)=\lambda^{n}+c_{1} \lambda^{n-1}+\cdots+c_{n-1} \lambda+c_{n}$

$P_{i}(\lambda)=\lambda^{i}+c_{1}^{i} \lambda^{i-1}+\cdots+c_{i-1}^{i} \lambda+c_{i}^{i} \quad 1 \leq i \leq n$
The algorithm for calculating the coefficients of the characteristic polynomial of symmetric tridiagonal matrix $[A]$ is presented in Table 2 [22].

$C_{k n}$ is the $k^{\text {th }}$ characteristic polynomial coefficient of symmetric tridiagonal matrix $(n \times n)$. The coefficients of matrix $(7 \times 7)$ of Eq. (2) are calculated by the La Budde's method. Results obtained by this algorithm are summarised in Table 3.

Table 3. Coefficients of symmetric tridiagonal matrix $(7 \times 7)$ by La Budde's method

\begin{tabular}{|c|c|c|c|c|c|c|c|}
\hline & $C_{17}$ & $C_{27}$ & $C_{37}$ & $C_{47}$ & $C_{57}$ & $C_{67}$ & $C_{77}$ \\
\hline & -2 & & \multicolumn{3}{|c|}{$\begin{array}{l}\text { Decreasing of the } \\
\text { polynominal degree }\end{array}$} & & \\
\hline & -4 & 3 & & & & & \\
\hline & -6 & 10 & -4 & & & & \\
\hline & -8 & 21 & -20 & 5 & & & \\
\hline & -10 & 36 & -56 & 35 & -6 & & \\
\hline & -12 & 55 & -120 & 126 & -56 & 7 & \\
\hline $\mathrm{n}=7$ & -13 & 66 & -165 & 210 & -126 & 28 & -1 \\
\hline
\end{tabular}

The calculation of coefficients of the characteristic polynomial by using the La Budde's method requires determination of intermediate values, which serve only to obtain the coefficients of the considered polynomial. On the other hand, the proposed method provides coefficients of the considered polynomial and also those of the characteristic polynomials of lower degrees. Moreover, all coefficients of the polynomials characteristic of all matrices of any order related to Eq. (2) are deduced from the proposed algorithm. This database can be exploited without any iteration, and repetition of calculations is omitted.

\subsection{Eigenvectors}

Each angular frequency $\omega_{\mathrm{i}}$ has a corresponding eigenvector derived from the equation:

$\left[[K]-\omega_{i}^{2}[M]\right]\left\{\Phi_{i}\right\}=0$

Table 2. La Budde's method for symmetric tridiagonal matrix ( $\mathrm{n} \times \mathrm{n}$ )

\begin{tabular}{|c|c|c|c|c|c|c|}
\hline & $C_{1 \mathrm{n}}$ & $C_{2 n}$ & $C_{3 n}$ & $\ldots$ & $C_{n-1, n}$ & $C_{n, n}$ \\
\hline 1 & $c_{11}=-a_{1}$ & & & & & \\
\hline 2 & & $a_{1} a_{2}-b_{2}^{2}$ & & & & \\
\hline 3 & & & $-a_{3} c_{22}-b_{3}{ }^{2} c_{11}$ & & & \\
\hline & & & & $\ldots$ & & \\
\hline \multirow[t]{2}{*}{$\mathbf{k}$} & $c_{1 k-1}-a_{k}$ & $c_{2, k-1}-a_{k} c_{1, k-1}-b_{k}^{2}$ & $c_{3, k-1}-a_{k} c_{2, k-1}-b_{k}{ }^{2} c_{1, k-2}$ & & & \\
\hline & & & & & $-a_{n-1} c_{n-2, n-2}-b_{n-1}{ }^{2} c_{n-3, n-3}$ & \\
\hline $\mathbf{n}$ & $c_{1 n-1}-a_{n}$ & $c_{2, n-1}-a_{n} c_{1, n-1}-b_{n}^{2}$ & $c_{3, n-1}-a_{n} c_{2, n-1}-b_{n}^{2} c_{1, n-2}$ & $\ldots$ & $c_{n-1, n-1}-a_{n} c_{n-2, n-1}-b_{n}^{2} c_{n-3, n-2}$ & $-a_{n} c_{n-1, n-1}-b_{n}^{2} c_{n-2, n-2}$ \\
\hline
\end{tabular}


Using the same arrangements as for Eqs. (1), (3) and (5), Eq. (13) becomes:

$\left[[\bar{K}]-\alpha_{i}[l]\right]\left\{\Phi_{i}\right\}=0$

The eigenvector determination requires the use a property of a tridiagonal matrix as described below:

$P_{n}(\alpha)=\left\|\begin{array}{ccccc}(2-\alpha) & -1 & 0 & 0 & 0 \\ -1 & (2-\alpha) & \ldots & 0 & 0 \\ 0 & \ldots . & \ldots . . & \ldots & 0 \\ 0 & 0 & \ldots . & (2-\alpha) & -1 \\ 0 & 0 & 0 & -1 & (1-\alpha)\end{array}\right\|_{n \times n}$

$P_{n}(\alpha)=(2-\alpha) \|\left(\begin{array}{ccccc}(2-\alpha) & -1 & 0 & 0 & 0 \\ -1 & (2-\alpha) & \ldots . & 0 & 0 \\ 0 & \ldots . & \ldots . . & \ldots & 0 \\ 0 & 0 & \ldots . & (2-\alpha) & -1 \\ 0 & 0 & 0 & -1 & (1-\alpha) \|_{(n-1) \times(n-1)}\end{array}\right.$

$$
-(-1)\left\|\begin{array}{ccccc}
-1 & -1 & 0 & 0 & 0 \\
0 & (2-\alpha) & -1 & 0 & 0 \\
0 & .-1 & \ldots . . & \ldots & 0 \\
0 & 0 & \ldots & (2-\alpha) & -1 \\
0 & 0 & 0 & -1 & (1-\alpha)
\end{array}\right\|_{(n-1) x(n-1)}
$$

$P_{n}(\alpha)=(2-\alpha) P_{(n-1)}+(-1) P_{(n-2)}+\left\|\begin{array}{ccccc}0 & -1 & 0 & 0 & 0 \\ 0 & (2-\alpha) & -1 & 0 & 0 \\ 0 & -1 & (2-\alpha) & \ldots & 0 \\ 0 & 0 & \ldots . & (2-\alpha) & -1 \\ 0 & 0 & 0 & -1 & (1-\alpha)\end{array}\right\|$

The last matrix of Eq. (17) with a null column leads to the cancellation of its determinant. By applying the relationship of Eq. (17), the polynomial $P_{n}(\alpha)$ can be written in the following form:

$P_{n}(\alpha)=\left\{\begin{array}{l}P_{0}(\alpha)=1 \\ P_{1}(\alpha)=1-\alpha \\ P_{n}(\alpha)=(2-\alpha) P_{n-1}(\alpha)-P_{n-2}(\alpha) \quad n \geq 2\end{array}\right.$

The eigenvector $\left\{\Phi_{i}\right\}$ satisfies Eq. (14). It is also presented in the form of Eq. (19):

$\left[\begin{array}{ccccccccc}\left(2-\alpha_{i}\right) & -1 & 0 & 0 & 0 & 0 & 0 & 0 & 0 \\ -1 & \left(2-\alpha_{i}\right) & \ldots & 0 & 0 & 0 & 0 & 0 & 0 \\ 0 & \vdots & \ddots & 0 & 0 & 0 & 0 & 0 & 0 \\ \vdots & 0 & -1 & \left(2-\alpha_{i}\right) & -1 & 0 & 0 & 0 & 0 \\ 0 & 0 & 0 & -1 & \left(2-\alpha_{i}\right) & -1 & 0 & 0 & 0 \\ 0 & 0 & 0 & 0 & -1 & \ddots & \cdots & 0 & 0 \\ 0 & 0 & 0 & 0 & 0 & \vdots & \ddots & 0 & \vdots \\ 0 & 0 & 0 & 0 & 0 & 0 & -1 & \left(2-\alpha_{i}\right) & -1 \\ 0 & 0 & 0 & \cdots & 0 & 0 & 0 & -1 & \left(1-\alpha_{i}\right)\end{array}\right]\left\{\begin{array}{c}\phi_{1 i} \\ \phi_{2 i} \\ \vdots \\ \phi_{n-(k+1), i} \\ \phi_{n-k, i} \\ \phi_{n-(k-1), i} \\ \vdots \\ \phi_{n-1, i} \\ \phi_{n, i}\end{array}\right\}=\left\{\begin{array}{c}0 \\ 0 \\ \vdots \\ 0 \\ 0 \\ 0 \\ \vdots \\ 0 \\ 0\end{array}\right\}$

The $\mathrm{k}^{\text {th }}$ and $\mathrm{n}^{\text {th }}$ lines of Eq. (19) permit deduction of these two relationships:

$\left\{\begin{array}{l}\phi_{n-1, i}=\left(1-\alpha_{i}\right) \phi_{n, i} \\ \phi_{n-(k+1), i}=\left(2-\alpha_{i}\right) \phi_{n-k, i}-\phi_{n-(k-1), i} k=1, \ldots, n-2\end{array}\right.$

In order to determine the eigenvector, it is necessary to assign a value of any element of the vector and deduce the rest of elements. Generally, the unit value is taken to be a random value. If $\Phi_{n, i}=1$; from the $n^{\text {th }}$ line of Eq. (19), and using the relationship presented by Eq. (18), $\Phi_{n-1, i}$ is obtained as follows:

$\phi_{n-1, i}=\left(1-\alpha_{i}\right) \phi_{n, i}=P_{1}\left(\alpha_{i}\right)$

The line ( $n-1)$ of Eq. (19) leads to $\phi_{n-2, i}$ as mentioned in Eq. (22):

$\phi_{n-2, i}=\left(2-\alpha_{i}\right) \phi_{n-1, i}-\phi_{n, i}=\left(2-\alpha_{i}\right) P_{1}\left(\alpha_{i}\right)-P_{0}\left(\alpha_{i}\right)=P_{2}\left(\alpha_{i}\right)$

Successively, by the same reasoning, all elements are determined:

$\phi_{n-k, i}=P_{k}\left(\alpha_{i}\right) k=0, \ldots,(\mathrm{n}-1)$

Thus, a corresponding eigenvector of a building of " $n$ " identical storeys is determined for each value of $\alpha_{i}$. In fact, by replacing the value of $\alpha_{i}$ in polynomials related to 1 to $n-1$ storeys, the corresponding eigenvector, normalized to the first element, can easily be obtained:

$\left\{\Phi_{i}\right\}=\left[\mathrm{P}_{\mathrm{n}-1}\left(\alpha_{\mathrm{i}}\right) ; \mathrm{P}_{\mathrm{n}-2}\left(\alpha_{\mathrm{i}}\right) ; \ldots ; \mathrm{P}_{1}\left(\alpha_{\mathrm{i}}\right) ; 1\right] \mathrm{T} / \mathrm{P}_{\mathrm{n}-1}\left(\alpha_{\mathrm{i}}\right)$

\subsection{Modal participation factor and Modal Mass Participation Ratio (MMPR)}

The modal participation factor $\Gamma_{\mathrm{i}}$ is defined in Eq. [23]:

$\Gamma_{i}=\frac{\left\{\Phi_{i}\right\}^{\top}[M]\{1\}}{\left\{\Phi_{i}\right\}^{\top}[M]\left\{\Phi_{i}\right\}}$

It can clearly be seen from Eq. (25) that the modal participation factor varies depending on the normalization of the mode shape. If $\left\{\Phi_{i}\right\}$, is the $i^{\text {th }}$ mode shape normalized to $j^{\text {th }}$ element, the relationship between vectors $\left\{\Phi_{i}\right\}_{i}$ and $\left\{\Phi_{i}\right\}_{k}$ is:

$\left\{\Phi_{i}\right\}_{j}=\left(\Phi_{k i}\right)_{j}\left\{\Phi_{i}\right\}_{k}$

where $\left(\Phi_{k i}\right)_{j}$ is the $k^{\text {th }}$ element of the $i^{i \text { th }}$ mode shape normalized to ${ }^{\text {th }}$ element. Eq. (28) is obtained by replacing the expression of $\left\{\Phi_{i}\right\}_{j}$ in Eq. (25):

$\left(\Gamma_{i}\right)_{j}=\frac{1}{\left(\Phi_{k i}\right)_{j}} \frac{\left\{\Phi_{i}\right\}_{k}^{T}[M]\{1\}}{\left\{\Phi_{i}\right\}_{k}^{T}[M]\left\{\Phi_{i}\right\}_{k}}$ 
$\left(\Gamma_{i}\right)_{j}=\frac{\left(\Gamma_{i}\right)_{k}}{\left(\Phi_{k i}\right)_{j}}$

$\left(\Gamma_{i}\right)_{k}$ is the modal participation factor of the $i^{\text {th }}$ mode obtained using the $i^{t^{t h}}$ mode shape normalized to $\mathrm{k}^{\text {th }}$ element.

It can be noticed that the modal participation factor is different from the Modal Mass Participation Ratio, i.e. the ratio between the $i^{\text {th }}$ effective modal mass $\left(\overline{\mathrm{M}}_{\mathrm{i}}\right)$ and the total mass [23].

$\left(\bar{M}_{\mathrm{i}}\right)=\Gamma_{\mathrm{i}}^{2}\left\{\Phi_{\mathrm{i}}\right\}^{\top}[\mathrm{M}]\left\{\Phi_{\mathrm{i}}\right\}$

The effective mass is independent of the normalization mode shape as it appears in the following. $\left(\bar{M}_{\mathrm{i}}\right)$ is the $i^{\text {th }}$ effective modal mass obtained using $\left\{\Phi_{i}\right\}_{j}$, which is the $\mathrm{i}^{\text {th }}$ mode shape normalized to the $j^{\text {th }}$ element.

$\left(\bar{M}_{i}\right)_{j}=\left(\Gamma_{i}\right)_{j}^{2}\left\{\Phi_{i}\right\}_{j}^{T}[M]\left\{\Phi_{i}\right\}_{j}$

Substituting Eqs. (26) and (28) into Eq. (30) leads to:

$\left(\bar{M}_{i}\right)_{j}=\left(\Gamma_{i}\right)_{k}^{2}\left\{\Phi_{i}\right\}_{k}^{T}[M]\left\{\Phi_{i}\right\}_{k}=\left(\bar{M}_{i}\right)_{k}$

It can be seen from Eq. (31) that the effective modal mass and the Modal Mass Participation Ratio are independent of the normalization of the mode shape.

Two additional cases of buildings frequently encountered are studied in order to expand applicability of this approach. These buildings represent buildings having either the first or the last storey different from the other storeys (refer to chapters 3 and 4).

\section{Building in which the first storey is different from other storeys}

In this case, all storeys are considered as identical except for the first storey. The stiffness and mass of the first storey are denoted $k_{1}$ and $m_{1}$, respectively, while for each upper storey the stiffness is marked $k$ and the corresponding mass is $\mathrm{m}$. For this type of building, the polynomial coefficients are calculated exactly as in the case of identical storeys building by substituting the cell $a_{11}=1$ in Table 1 by the value $b=k / k_{1}$ in the same cell in Table 4 , and the content of the cell $\mathrm{a}_{22}=1$ of Table 1 by ab in the corresponding cell in Table 4, where $a=m_{1} / m$.

However, all coefficients corresponding to higher order polynomials $P_{n}(\alpha)$ will be automatically deduced from the first two lines of Table 4. It can be noted that the polynomial has alternated signs. Thus obtained roots $\alpha_{i}$ of the polynomial of degree $n$ allow determination of angular frequencies $\omega_{i}$ of the structure by $\omega_{i}^{2}=\alpha_{i} \omega_{0}^{2}$, and the eigenvector $\left\{\Phi_{i}\right\}$ corresponding to $\alpha_{i}$ is then obtained by using Eq. (24).

\section{Building in which the last storey is different from other storeys}

In this case, all storeys are considered to be identical except for the last storey. This means that the stiffness $k_{n}$ and the mass $m_{n}$ of the last storey are different from those of other storeys, $\mathrm{k}$ and $\mathrm{m}$.

Table 4. Polynomial coefficients $P_{n}(\alpha)$ for RC frame building in which the first storey is different from other storeys

\begin{tabular}{|c|c|c|c|c|c|c|}
\hline $\begin{array}{l}\text { Number } \\
\text { of storeys }\end{array}$ & & & & & \multirow[b]{2}{*}{$\mathrm{b}=\mathrm{k} / \mathrm{k}_{1}$} & \\
\hline 0 & $b$ & & & & & \\
\hline 1 & 1 & $a b$ & & & $\mathrm{a}=\mathrm{m}_{1} / \mathrm{m}$ & \\
\hline 2 & 1 & $a b+b+1$ & $a b$ & & $\omega_{0}^{2}=\mathrm{k} / \mathrm{m}$ & \\
\hline 3 & 1 & $a b+2 b+3$ & $3 a b+b+1$ & $a b$ & $\alpha=\omega^{2} / \omega_{0}^{2}$ & \\
\hline 4 & 1 & $a b+3 b+6$ & $6 a b+4 b+5$ & $5 a b+b+1$ & $a b$ & \\
\hline 5 & 1 & $a b+4 b+10$ & $10 a b+10 b+15$ & $15 a b+6 b+7$ & $7 a b+b+1$ & $a b$ \\
\hline
\end{tabular}

Table 5. Polynomial coefficients $P_{n}(\alpha)$ for RC frame building, in which the last storey is different from other storeys

\begin{tabular}{|c|c|c|c|c|c|c|}
\hline $\begin{array}{c}\text { Number } \\
\text { of storeys }\end{array}$ & & & & $\begin{array}{l}\text { f the } \\
\text { degree }\end{array}$ & \multirow[b]{2}{*}{$b^{\prime}=k / k_{n}$} & \\
\hline 0 & $a^{\prime}$ & & & \multirow{3}{*}{$\begin{array}{l}a^{\prime}=m_{n} / m \\
\alpha=\omega^{2} / \omega_{0}^{2}\end{array}$} & & \\
\hline 1 & 1 & $a^{\prime} b^{\prime}$ & & & \multirow[t]{3}{*}{$\omega_{0}^{2}=\mathrm{k} / \mathrm{m}$} & \\
\hline 2 & 1 & $a^{\prime} b^{\prime}+a^{\prime}+1$ & $a^{\prime} b^{\prime}$ & & & \\
\hline 3 & 1 & $a^{\prime} b^{\prime}+2 a^{\prime}+3$ & $3 a^{\prime} b^{\prime}+a^{\prime}+1$ & $a^{\prime} b^{\prime}$ & & \\
\hline 4 & 1 & $a^{\prime} b^{\prime}+3 a^{\prime}+6$ & $6 a^{\prime} b^{\prime}+4 a^{\prime}+5$ & $5 a^{\prime} b^{\prime}+a^{\prime}+1$ & $a^{\prime} b^{\prime}$ & \\
\hline 5 & 1 & $a^{\prime} b^{\prime}+4 a^{\prime}+10$ & $10 a^{\prime} b^{\prime}+10 a^{\prime}+15$ & $15 a^{\prime} b^{\prime}+6 a^{\prime}+7$ & $7 a^{\prime} b^{\prime}+a^{\prime}+1$ & $a^{\prime} b^{\prime}$ \\
\hline
\end{tabular}


The procedure for determining coefficients of the polynomial $P_{n}$ $(\alpha)$ is similar to the one explained in Section 3. In this case, the constant (b) should be substituted by ( $\left.a^{\prime}\right)$ and (a) by ( $\left.b^{\prime}\right)$, where $a^{\prime}=m_{n} / m$ and $b^{\prime}=k / k_{n}$. It can be noted that the polynomial has alternate signs. Angular frequencies and eigenvectors are determined by the same way as explained in chapter 3 .

\section{Vibration modes for RC frame building of identical storeys}

In this section, the case of a building with identical storeys is studied. Indeed, all natural angular frequencies, modal participation factors, modal mass participation ratio and eigenvectors, are determined. These parameters are calculated for nine buildings of two to ten storeys; this can be extended to a higher number of storeys (more than ten). The eigenvectors and modal participation factors are independent of stiffness and mass values, but are dependent on the ratio of two successive storeys characteristics ( $\mathrm{k}$ and $\mathrm{m}$ ).

Results are presented in Tables 6 and 7. To avoid repeating the same calculation procedure, this database can be investigated directly from Tables 6 and 7, or by creating a computer subroutine. The values of the modal mass participation ratio presented in Tables 6 and 7 are in accordance with the results obtained by Palermo \& al. [24]. In fact, the value of MMPR corresponding to the first mode is located within the interval [0.82; 0.88] related to 5 storey buildings or greater. In addition, the summation of the MMPR deduced from three first modes of vibration is greater than $90 \%$.

\section{Results and discussions}

\subsection{Case of RC frame buildings of identical storeys}

\subsubsection{Angular frequencies}

A comparison with an existing method is made in order to validate the proposed method. The referenced method is Jacobi method revised and reformulated by Hochstenbach [8]. This method allows determination of natural modes of vibration by an iterative process based on diagonalisation of stiffness and mass matrices. For each iteration, a matrix noted $\left[\mathrm{Q}^{k}\right]$ permits elimination of matrix elements $k_{i j}^{k+1}$ and $m_{i j}^{k+1}$ as follows:

$$
\left[K^{(k+1)}\right]=\left[Q^{k}\right]^{T}\left[K^{k}\right]\left[Q^{k}\right] ;\left[M^{(k+1)}\right]=\left[Q^{k}\right]^{T}\left[M^{k}\right]\left[Q^{k}\right]
$$

where $\left[\mathrm{Q}^{\mathrm{k}}\right]$ has the form:

$$
\left[Q^{k}\right]=\left[\begin{array}{cccccc}
1 & 0 & 0 & \cdots & 0 & 0 \\
0 & 1 & 0 & \cdots & \text { a } & 0 \\
0 & 0 & \ddots & 0 & 0 & 0 \\
\vdots & \vdots & 0 & 1 & 0 & 0 \\
0 & \mathrm{~b} & 0 & 0 & 1 & 0 \\
0 & 0 & 0 & 0 & 0 & 1
\end{array}\right] j
$$

The constants "a" and "b" are determined by applying the value of zero simultaneously to $k_{i j}^{k+1}$ and $m_{i j}^{k+1}$ (see Eq. (34)):

$\left\{\begin{array}{l}a=-\frac{\left(k_{i i} m_{j j}-m_{i j} k_{i j}\right)-\sqrt{\left(k_{i i} m_{j j}-m_{i j} k_{j j}\right)^{2}+4\left(k_{i j} m_{i j}-m_{i j} k_{i j}\right)\left(k_{j j} m_{i j}-m_{j j} k_{i j}\right)}}{2\left(k_{i j} m_{i j}-m_{i j} k_{i j}\right)} \\ b=\frac{\left(k_{i j} m_{j j}-m_{i j} k_{j j}\right)-\sqrt{\left(k_{i j} m_{j j}-m_{i j} k_{i j}\right)^{2}+4\left(k_{i j} m_{i j}-m_{i j} k_{i j}\right)\left(k_{j j} m_{i j}-m_{j j} k_{i j}\right)}}{2\left(k_{i j} m_{i j}-m_{i j} k_{i j}\right)}\end{array}\right.$

After each iteration, extra diagonal elements are compared between themselves and to the imposed precision using the expression:

$\varepsilon_{i j}=\frac{\left|k_{i j}\right|}{\sqrt{k_{i i} k_{j j}}} \leq 10^{-p}$

Elements $k_{i j}$ i $m_{i j^{\prime}}$ to be eliminated at the next iteration correspond to the maximum value of $\varepsilon_{i j}$ It should be noted that the required accuracy of Jacobi method depends on the value of $p$.

After diagonalisation of stiffness and mass matrices, pulsations are determined by $\omega_{i}{ }^{2}=\mathrm{k}_{\mathrm{ii}}{ }^{d} / \mathrm{m}_{\mathrm{ii}}{ }^{\mathrm{d}}$, where $\mathrm{k}_{\mathrm{ii}}{ }^{\mathrm{d}}$ and $\mathrm{m}_{\mathrm{ii}}{ }^{\mathrm{d}}$ are the elements of stiffness and the mass of diagonalised matrices, respectively. The eigenvectors matrix $[\phi]$ is obtained by:

\begin{tabular}{|c|c|c|c|c|c|c|c|c|c|}
\hline Number of storeys & \multicolumn{2}{|c|}{2} & \multicolumn{3}{|c|}{3} & \multicolumn{4}{|c|}{4} \\
\hline MPF & 0.7236 & 0.2764 & 0.5432 & 0.3492 & 0.1076 & 0.4307 & 0.3333 & 0.1840 & 0.0520 \\
\hline MMPR [\%] & 94.72 & 5.28 & 91.41 & 7.49 & 1.10 & 89.34 & 8.33 & 1.96 & 0.37 \\
\hline$\left(\omega_{i} / \omega_{0}\right)^{2}$ & 0.3820 & 2.6180 & 0.19810 & 1.5550 & 3.2470 & 0.1206 & 1.0000 & 2.3473 & 3.5321 \\
\hline \multirow{4}{*}{ Eigenvector } & 1.0000 & 1.0000 & 1.0000 & 1.0000 & 1.0000 & 1.0000 & 1.0000 & 1.0000 & 1.0000 \\
\hline & 1.6179 & -0.6180 & 1.8020 & 0.4450 & -1.2470 & 1.8793 & 1.0000 & -0.3473 & -1.5321 \\
\hline & & & 2.2471 & -0.8019 & 0.5550 & 2.5319 & 0.0000 & -0.8794 & 1.3473 \\
\hline & & & & & & 2.8792 & -1.0000 & 0.6527 & -0.5321 \\
\hline
\end{tabular}

Table 6. Vibration modes for RC frame buildings of $\mathbf{2}$ to $\mathbf{7}$ identical storeys 
Table 6. Vibration modes for RC frame buildings of $\mathbf{2}$ to $\mathbf{7}$ identical storeys - extension

\begin{tabular}{|c|c|c|c|c|c|c|c|}
\hline Number of storeys & \multicolumn{7}{|c|}{5} \\
\hline MPF & 0.3563 & \multicolumn{2}{|c|}{0.3007} & 0.208 & \multicolumn{2}{|c|}{0.1062} & 0.0288 \\
\hline MMPR [\%] & 87.95 & \multicolumn{2}{|c|}{8.72} & 2.42 & \multicolumn{2}{|c|}{0.75} & 0.16 \\
\hline$\left(\omega_{i} / \omega_{0}\right)^{2}$ & 0.0810 & \multicolumn{2}{|c|}{0.6903} & 1.7154 & \multicolumn{2}{|c|}{2.8308} & 3.6825 \\
\hline \multirow{5}{*}{ Eigenvector } & 1.0000 & \multicolumn{2}{|c|}{1.0000} & 1.0000 & \multicolumn{2}{|c|}{1.0000} & 1.0000 \\
\hline & 1.9188 & \multicolumn{2}{|c|}{1.3097} & 0.2846 & \multicolumn{2}{|c|}{-0.8308} & -1.6825 \\
\hline & 2.6823 & \multicolumn{2}{|c|}{0.7153} & -0.9190 & \multicolumn{2}{|c|}{-0.3097} & 1.8308 \\
\hline & 3.2284 & \multicolumn{2}{|c|}{-0.3728} & -0.5462 & \multicolumn{2}{|c|}{1.0882} & -1.3979 \\
\hline & 3.5130 & & 36 & 0.7635 & & 944 & 0.5211 \\
\hline Number of storeys & & & & 6 & & & \\
\hline MPF & 0.3032 & 0.2690 & & & & 0.0667 & 0.0176 \\
\hline MMPR [\%] & 86.96 & 8.91 & & & & 0.35 & 0.08 \\
\hline$\left(\omega_{i} / \omega_{0}\right)^{2}$ & 0.0581 & 0.5030 & & & & 3.1361 & 3.7710 \\
\hline & 1.0000 & 1.0000 & & & & 1.0000 & 1.0000 \\
\hline & 1.9421 & 1.4970 & & & 11 & -1.1361 & -1.7709 \\
\hline Fironuector & 2.7713 & 1.2410 & & & 19 & 0.2908 & 2.1361 \\
\hline Ligelluectu & 3.4394 & 0.3609 & & & & 0.8058 & -2.0120 \\
\hline & 3.9077 & -0.7008 & & & & -1.2062 & 1.4269 \\
\hline & 4.1488 & -1.410 & & & 80 & 0.5647 & -0.5150 \\
\hline Number of storeys & & & & 7 & & & \\
\hline MPF & 0.2638 & 0.2412 & 0.2000 & 0.1471 & 0.0921 & 0.0443 & 0.0115 \\
\hline MMPR [\%] & 86.21 & 9.02 & 2.86 & 1.18 & 0.50 & 0.19 & 0.04 \\
\hline$\left(\omega_{i} / \omega_{0}\right)^{2}$ & 0.04371 & 0.38197 & 1.00000 & 1.79095 & 2.61803 & 3.33827 & 3.82709 \\
\hline & 1.0000 & 1.0000 & 1.0000 & 1.0000 & 1.0000 & 1.0000 & 1.0000 \\
\hline & 1.9563 & 1.6181 & 1.0000 & 0.2091 & -0.6180 & -1.3382 & -1.8271 \\
\hline & 2.8271 & 1.6181 & 0.0000 & -0.9563 & -0.6180 & 0.7909 & 2.3383 \\
\hline Eigenvector & 3.5744 & 1.0000 & -1.0000 & -0.4090 & 1.0000 & 0.2798 & -2.4452 \\
\hline & 4.1654 & 0.0000 & -1.0000 & 0.8708 & -0.0000 & -1.1653 & 2.1292 \\
\hline & 4.5744 & -1.0000 & 0.0000 & 0.5910 & -1.0000 & 1.2798 & -1.4452 \\
\hline & 4.7835 & -1.6181 & 1.0000 & -0.7472 & 0.6180 & -0.5473 & 0.5112 \\
\hline
\end{tabular}

Table 7. Vibration modes for RC frame buildings of 8 to 10 identical storeys

\begin{tabular}{|c|c|c|c|c|c|c|c|c|}
\hline Number of storeys & & & & & & & & \\
\hline MPF & 0.2339 & 0.2177 & 0.1884 & 0.1499 & 0.1067 & 0.065 & 0.0306 & 0.0078 \\
\hline MMPR[\%] & 85.63 & 9.08 & 2.97 & 1.29 & 0.61 & 0.28 & 0.11 & 0.03 \\
\hline$\left(\omega_{i} / \omega_{0}\right)^{2}$ & 0.0341 & 0.2996 & 0.7947 & 1.4527 & 2.1845 & 2.8915 & 3.4780 & 3.8645 \\
\hline \multirow{8}{*}{ Eigenvector } & 1.0000 & 1.0000 & 1.0000 & 1.0000 & 1.0000 & 1.0000 & 1.0000 & 1.0000 \\
\hline & 1.9660 & 1.7004 & 1.2053 & 0.5473 & -0.1846 & -0.8915 & -1.4780 & -1.8650 \\
\hline & 2.8650 & 1.8913 & 0.4527 & -0.7004 & -0.9659 & -0.2053 & 1.1845 & 2.4780 \\
\hline & 3.6665 & 1.5158 & -0.6597 & -0.9307 & 0.3628 & 1.0745 & -0.2727 & -2.7565 \\
\hline & 4.3431 & 0.6861 & -1.2478 & 0.1910 & 0.8990 & -0.7526 & -0.7814 & 2.6626 \\
\hline & 4.8718 & -0.3490 & -0.8442 & 1.0353 & -0.5287 & -0.4036 & 1.4277 & -2.2091 \\
\hline & 5.2346 & -1.2797 & 0.2303 & 0.3756 & -0.8014 & 1.1123 & -1.3287 & 1.4573 \\
\hline & 5.4191 & -1.8269 & 1.1217 & -0.8297 & 0.6766 & -0.5881 & 0.5362 & -0.5087 \\
\hline
\end{tabular}


Table 7. Vibration modes for RC frame buildings of 8 to 10 identical storeys - extension

\begin{tabular}{|c|c|c|c|c|c|c|c|c|c|c|c|c|c|}
\hline Number of storeys & \multicolumn{13}{|c|}{9} \\
\hline MPF & 0.2090 & 0.1979 & 0.1765 & \multicolumn{2}{|c|}{0.1476} & \multicolumn{2}{|c|}{0.114} & \multicolumn{2}{|c|}{0.0795} & \multicolumn{2}{|c|}{0.0476} & 0.0222 & 0.0057 \\
\hline MMPR [ \%] & 85.17 & 9.12 & 3.04 & \multicolumn{2}{|c|}{1.37} & \multicolumn{2}{|c|}{0.69} & \multicolumn{2}{|c|}{0.35} & \multicolumn{2}{|r|}{0.17} & 0.07 & 0.02 \\
\hline$\left(\omega_{i} / \omega_{0}\right)^{2}$ & 0.0273 & 0.2411 & 0.6454 & \multicolumn{2}{|c|}{1.1966} & \multicolumn{2}{|c|}{1.8348} & \multicolumn{2}{|c|}{2.4910} & \multicolumn{2}{|c|}{3.0939} & 3.5783 & 3.8916 \\
\hline \multirow{9}{*}{ Eigenvector } & 1.0000 & 1.0000 & 1.0000 & \multicolumn{2}{|c|}{1.0000} & \multicolumn{2}{|c|}{1.0000} & \multicolumn{2}{|c|}{1.0000} & \multicolumn{2}{|r|}{1.0000} & 1.0000 & 1.0000 \\
\hline & 1.9727 & 1.7589 & 1.3545 & \multicolumn{2}{|c|}{0.8034} & \multicolumn{2}{|c|}{0.1652} & \multicolumn{2}{|c|}{-0.4910} & \multicolumn{2}{|c|}{-1.0939} & -1.5783 & -1.8916 \\
\hline & 2.8915 & 2.0938 & 0.8348 & \multicolumn{2}{|c|}{-0.3546} & -0 & 727 & & 589 & & 0.1966 & 1.4910 & 2.5782 \\
\hline & 3.7315 & 1.9240 & -0.2237 & -1.08 & & -0 & 258 & & 636 & & 0.8788 & -0.7749 & -2.9855 \\
\hline & 4.4697 & 1.2904 & -1.1379 & -0.5 & & & & & 349 & & 1.1579 & -0.2680 & 3.0692 \\
\hline & 5.0859 & 0.3458 & -1.3176 & 0.67 & & & & & 280 & & 0.3878 & 1.1978 & -2.8203 \\
\hline & 5.5635 & -0.6822 & -0.6469 & 1.05 & & -0 & +00 & & 698 & & 0.7337 & -1.6226 & 2.2658 \\
\hline & 5.8893 & -1.5458 & 0.4413 & 0.17 & & -0 & 163 & & 447 & & 1.1904 & 1.3630 & -1.4658 \\
\hline & 6.0544 & -2.0367 & 1.2447 & -0.9 & & & & & 5336 & & 0.5685 & -0.5286 & 0.5069 \\
\hline Number of storeys & & & & & & & & & & & & & \\
\hline MPF & 0.1894 & 0.1810 & 0.1651 & 0.1429 & & 164 & 0.0 & & 0.060 & & 0.0359 & 0.0165 & 0.0042 \\
\hline MMPR [\%] & 84.79 & 9.14 & 3.09 & 1.43 & & 75 & & & 0.22 & & 0.11 & 0.05 & 0.01 \\
\hline$\left(\omega_{i} / \omega_{0}\right)^{2}$ & 0.0223 & 0.1981 & 0.5339 & 1.0000 & & 550 & 2.1 & & 2.7307 & & 3.2470 & 3.6525 & 3.9112 \\
\hline & 1.0000 & 1.0000 & 1.0000 & 1 & & 000 & 1.0 & & 1.0000 & & 1.0000 & 1.0000 & 1.0000 \\
\hline & 1.9773 & 1.8019 & 1.4661 & 1 & & 451 & 0.1 & & -0.730 & & -1.2470 & -1.6525 & -1.9111 \\
\hline & 2.9105 & 2.2469 & 1.1495 & 0 & & 3019 & -0.9 & & -0.466 & & 0.5550 & 1.7307 & 2.6524 \\
\hline & 3.7787 & 2.2469 & 0.2192 & -1 & & 3019 & 0.2 & & 1.0713 & & 0.5550 & -1.2074 & -3.1581 \\
\hline & 4.5624 & 1.8018 & -0.8282 & -1 & & 450 & 0.9 & & -0.316 & & -1.2470 & 0.2646 & 3.3831 \\
\hline veco & 5.2443 & 1.0000 & -1.4334 & 0 & & 000 & -0.4 & & -0.839 & & 1.0000 & 0.7702 & -3.3075 \\
\hline & 5.8090 & -0.0000 & -1.2733 & 1 & & 000 & -0.8 & & $0.930=$ & & 0.0000 & -1.5373 & 2.9381 \\
\hline & 6.2440 & -1.0000 & -0.4334 & 1 & & 000 & 0.5 & & 0.1601 & & -1.0000 & 1.7702 & -2.3075 \\
\hline & 6.5394 & -1.8019 & 0.6379 & 0 & & 450 & 0.7 & & -1.047 & & 1.2470 & -1.3879 & 1.4720 \\
\hline & 6.6888 & -2.2469 & 1.3686 & -1 & & 019 & -0.6 & & 0.6052 & & -0.5550 & 0.5232 & -0.5056 \\
\hline
\end{tabular}

$[\phi]=\left[Q^{1}\right] \times \cdots \times\left[Q^{n}\right] \cdot\left[\begin{array}{ccc}\frac{1}{\sqrt{m_{11}^{d}}} & \cdots & 0 \\ \vdots & \ddots & \vdots \\ 0 & \cdots & \frac{1}{\sqrt{m_{n n}^{d}}}\end{array}\right]$

Table 8. Example of a building of four identical storeys: Angular frequency

\begin{tabular}{|c|c|c|c|}
\cline { 2 - 3 } \multicolumn{1}{c|}{} & \multicolumn{2}{c|}{$\left(\omega_{\mathbf{i}} / \omega_{\mathbf{0}}\right)^{\mathbf{2}}$} & \multicolumn{1}{c}{} \\
\hline $\begin{array}{c}\text { Vibration } \\
\text { mode }\end{array}$ & $\begin{array}{c}\text { Proposed } \\
\text { method }\end{array}$ & $\begin{array}{c}\text { Jacobi } \\
\text { method }\end{array}$ & $\begin{array}{c}\text { Precision } \\
{[\%]}\end{array}$ \\
\hline $\mathbf{1}$ & 0.12061 & 0.12061 & 100.00 \\
\hline $\mathbf{2}$ & 1.00000 & 1.00000 & 100.00 \\
\hline $\mathbf{3}$ & 2.34730 & 2.34734 & 99.998 \\
\hline $\mathbf{4}$ & 3.53209 & 3.53205 & 99.999 \\
\hline
\end{tabular}

An example of a building of four identical storeys is treated herein. Results are summarized in Table 8. According to the results indicated in Table 8 , the comparison of angular frequencies between both methods has revealed a good correlation of the proposed method.

\subsubsection{Eigenvectors}

For the same example, the values of eigenvectors are also compared with those obtained by Jacobi method (see Table 9) and a very good precision has been established. The lower precision is $99,835 \%$.

\subsubsection{Comparison of fundamental angular frequencies for buildings having 2 through 5 storeys}

The fundamental angular frequencies, noted $\omega_{1}$, for buildings having 2 through 5 floors, are compared with those found by Jacobi method. The results of this study are shown in Table 10. 
Table 9. Example of a building of four identical storeys: Eigenvector

\begin{tabular}{|c|c|c|}
\hline Proposed method & Jacobi method & Precision [\%] \\
\hline$\left\{\Phi_{1}\right\}$ & $\left\{\Phi_{1}\right\}$ & \\
\hline 1.00000 & 1.00000 & 100.000 \\
\hline 1.87939 & 1.87962 & 99.988 \\
\hline 2.53210 & 2.53218 & 99.997 \\
\hline 2.87939 & 2.87962 & 99.992 \\
\hline$\left\{\Phi_{2}\right\}$ & $\left\{\Phi_{2}\right\}$ & \\
\hline 1.00000 & 1.00000 & 100.000 \\
\hline 1.00000 & 0.99968 & 99.968 \\
\hline 0.00001 & -0.00021 & - \\
\hline-1.00000 & -0.99961 & 99.961 \\
\hline$\left\{\Phi_{3}\right\}$ & $\left\{\Phi_{3}\right\}$ & \\
\hline 1.00000 & 1.00000 & 100.000 \\
\hline-0.34730 & -0.34754 & 99.931 \\
\hline-0.87939 & -0.87954 & 99.983 \\
\hline 0.65270 & 0.65301 & 99.953 \\
\hline$\left\{\Phi_{4}\right\}$ & $\left\{\Phi_{4}\right\}$ & \\
\hline 1.00000 & 1.00000 & 100.000 \\
\hline-1.53290 & -1.53202 & 99.943 \\
\hline 1.34730 & 1.34732 & 99.999 \\
\hline-0.53290 & -0.53202 & 99.835 \\
\hline
\end{tabular}

Table 10. Comparison of fundamental angular frequencies

\begin{tabular}{|c|c|c|c|}
\cline { 2 - 3 } \multicolumn{1}{c|}{} & \multicolumn{2}{c|}{$\left(\omega_{\mathrm{i}} / \omega_{\mathbf{0}}\right)^{2}$} & \multicolumn{1}{c}{} \\
\hline $\begin{array}{c}\text { Number of } \\
\text { storeys }\end{array}$ & $\begin{array}{c}\text { Proposed } \\
\text { method }\end{array}$ & $\begin{array}{c}\text { Jacobi } \\
\text { method }\end{array}$ & $\begin{array}{c}\text { Precision } \\
{[\%]}\end{array}$ \\
\hline $\mathbf{2}$ & 0.38197 & 0.38197 & 100.00 \\
\hline $\mathbf{3}$ & 0.19806 & 0.19806 & 100.00 \\
\hline $\mathbf{4}$ & 0.12061 & 0.12061 & 100.00 \\
\hline $\mathbf{5}$ & 0.08101 & 0.08102 & 99.99 \\
\hline
\end{tabular}

Once again, it appears that the lower precision is $99.99 \%$, which confirms the validity of the method.

\subsection{Case of RC frame buildings in which the first storey is different from other storeys}

\subsubsection{Fundamental angular frequencies}

Examples of buildings of 2, 3, 4 and 5 storeys are studied in this section. In this case, the stiffness and mass of the first storey is marked $k_{1}$ and $m_{1}$ respectively, while $k$ and $m$ marks are used for the upper storeys. The constants "a" and "b" are equal to $\mathrm{m}_{1} / \mathrm{m}$ and $\mathrm{k} / \mathrm{k}_{1}$, respectively. In order to verify the validity of the method, an example with $\mathrm{a}=1.25$ and $\mathrm{b}=0.9$ is considered. The corresponding coefficients of the polynomial $P_{n}(\alpha)$ are shown in Table 11.

Table 11. Coefficients of polynomials for RC frame building in which the first storey is different from other storeys, case of $a=1.25 ; b=0.9$

\begin{tabular}{|c|c|c|c|c|c|c|}
\hline $\begin{array}{l}\text { Number } \\
\text { of storeys }\end{array}$ & \multicolumn{5}{|c|}{$\begin{array}{l}\text { Ascending of the } \\
\text { polynominal degree }\end{array}$} & \\
\hline 0 & 0,9 & & & & & \\
\hline 1 & 1 & 1.125 & & & & \\
\hline 2 & 1 & 3.025 & 1.125 & & & \\
\hline 3 & 1 & 5.925 & 5.275 & 1.125 & & \\
\hline 4 & 1 & 9.825 & 15.35 & 7.525 & 1.125 & \\
\hline 5 & 1 & 14.725 & 35.25 & 29.275 & 9.775 & 1.125 \\
\hline
\end{tabular}

Once roots of polynomials are determined and fundamental angular frequencies are deduced, these angular frequencies are compared to those arising from the Jacobi method. The results of this comparison are presented in Table 12.

Table 12. Comparison of fundamental angular frequencies of RC frame buildings in which the first storey is different from other storeys: case of $a=1.25 ; b=0.9$

\begin{tabular}{|c|c|c|c|}
\cline { 2 - 3 } \multicolumn{1}{c|}{} & \multicolumn{2}{c|}{$\left(\omega_{\mathbf{i}} / \omega_{\mathbf{0}}\right)^{2}$} & \multicolumn{1}{c}{} \\
\hline $\begin{array}{c}\text { Number of } \\
\text { storeys }\end{array}$ & $\begin{array}{c}\text { Proposed } \\
\text { method }\end{array}$ & $\begin{array}{c}\text { Jacobi } \\
\text { method }\end{array}$ & $\begin{array}{c}\text { Precision } \\
{[\%]}\end{array}$ \\
\hline $\mathbf{2}$ & 0.38599 & 0.38599 & 100.00 \\
\hline $\mathbf{3}$ & 0.20433 & 0.20433 & 100.00 \\
\hline $\mathbf{4}$ & 0.12457 & 0.12467 & 99.92 \\
\hline $\mathbf{5}$ & 0.08346 & 0.08347 & 99.99 \\
\hline
\end{tabular}

The result of the comparison once again shows that the method is valid.

\subsection{Case of RC frame buildings in which the last storey is different from other storeys}

\subsubsection{Fundamental angular frequencies}

Examples of buildings of 2, 3, 4 and 5 storeys are studied in this section. In this case, the stiffness and mass of the last storey are denoted $k_{n}$ and $m_{n}$, respectively, while $k$ and $m$ are used for the lower storeys. The constants $a^{\prime}$ and $b^{\prime}$ are equal to $m_{n} / m$ and $k / k_{n^{\prime}}$ respectively. The case where $a^{\prime}=0.20$ and $b^{\prime}=4$ is considered for comparison. The corresponding coefficients of the polynomials $P_{n}(\alpha)$ are summarized in Table 13.

The roots of polynomials giving fundamental angular frequencies are compared to values obtained by Jacobi method related of buildings of 2 to 5 storeys. Results are presented in Table 14. These results put in evidence the accuracy of the proposed method. 
Table 13. Coefficients of polynomials for RC frame building in which the last storey is different from other storeys, case of $a^{\prime}=$ $0.20 ; b^{\prime}=4$

\begin{tabular}{|c|c|c|c|c|c|c|}
\hline $\begin{array}{c}\text { Number of } \\
\text { storeys }\end{array}$ & & \multicolumn{4}{|c|}{$\begin{array}{l}\text { Ascending of the } \\
\text { polynominal degree }\end{array}$} & \\
\hline 0 & 0.2 & & & & & \\
\hline 1 & 1 & 0.8 & & & & \\
\hline 2 & 1 & 2 & 0.8 & & & \\
\hline 3 & 1 & 4.2 & 3.6 & 0.8 & & \\
\hline 4 & 1 & 7.4 & 10.6 & 5.2 & 0.8 & \\
\hline 5 & 1 & 11.6 & 25 & 20.2 & 6.8 & 0.8 \\
\hline
\end{tabular}

Table 14. Comparison of fundamental angular frequencies of RC frame buildings in which the last storey is different from other storeys: case of $\mathrm{a}^{\prime}=\mathbf{0 . 2 0}$ and $\mathrm{b}^{\prime}=\mathbf{4}$

\begin{tabular}{|c|c|c|c|}
\cline { 2 - 3 } \multicolumn{1}{c|}{} & \multicolumn{2}{c|}{$\left(\omega_{\mathrm{i}} / \omega_{\mathbf{0}}\right)^{2}$} & \multicolumn{1}{c}{} \\
\hline $\begin{array}{c}\text { Number of } \\
\text { storeys }\end{array}$ & $\begin{array}{c}\text { Proposed } \\
\text { method }\end{array}$ & $\begin{array}{c}\text { Jacobi } \\
\text { method }\end{array}$ & $\begin{array}{c}\text { Precision } \\
{[\%]}\end{array}$ \\
\hline $\mathbf{2}$ & 0.69098 & 0.69098 & 100.00 \\
\hline $\mathbf{3}$ & 0.31927 & 0.31927 & 100.00 \\
\hline $\mathbf{4}$ & 0.17560 & 0.17599 & 99.78 \\
\hline $\mathbf{5}$ & 0.11009 & 0.11093 & 99.24 \\
\hline
\end{tabular}

\section{REFERENCES}

[1] Salama, M.I.: Estimation of period of vibration for concrete moment-resisting frame buildings, HBRC Journal, 11 (2015), pp. 11-21, https://doi.org/10.1016/j.hbrcj.2014.01.006

[2] Kim, J., Collins, K.R., Lim, Y.M.: An approximate formula to calculate the fundamental period of a fixed-free mass-spring system with varying mass and stiffness, Struc Eng and Mech, 25 (2007), pp. 717-732, https://doi.org/10.12989/sem.2007.25.6.717

[3] Joshi, S.G., Londhe, S.N., Kwatra, N.: Determination of natural periods of vibration using genetic programming, Earthq Struc, 6 (2014), pp. 201-216, https://doi.org/10.12989/eas.2014.6.2.201

[4] Sofi, M., Hutchinson, G.L, Duffield, C.: Review of Techniques for Predicting the Fundamental Period of Multi-Storey BuildingsEffects of Non structural Components, Int J Str Stab Dyn, 15 (2015) 2, https://doi.org/10.1142/S0219455414500394

[5] Maglajlić, Z., Simonović, G.: Approximation procedure for determining oscillation period of frame structures, GRAĐEVINAR, 59 (2007) 8, pp. 685-691.

[6] Ricci, P., Verderame, G.M., Manfredi, G.: Analytical investigation of elastic period of infilled RC MRF buildings, Eng Struc, 33 (2011), pp. 308-319, https://doi.org/10.1016/j.engstruct.2010.10.009

\section{Conclusion}

The method developed in this research work enables simple determination of all natural modes of vibration for three specific types of RC frame buildings (building having identical storeys, building in which the first storey is different from other storeys, and building in which the last storey is different from other storeys). Results obtained by means of the proposed method are compared to those obtained by Jacobi method. Precisions obtained through this comparison are very satisfactory. This puts into evidence the efficiency of the proposed method, which is characterized by simplicity. The computation was first conducted for buildings with 2 until 10 identical storeys, and conclusion is given via a table grouping all natural modes of vibration. This table can be used directly for structural dynamic analysis, and inserted in annex of a seismic design code of buildings. Using this procedure, structural engineers avoid unnecessary duplication of calculations related to this type of buildings.

In order to further extend area in which this method can be applied, two additional cases - considered as being the most common in practice - are also studied. These cases represent buildings having either the first or the last storey different from the other storeys.

A process giving all coefficients of the polynomial $P_{n}(\alpha)$ is highlighted for three above-mentioned specific types of RC frame buildings. Once roots of this polynomial are determined, the eigenvectors can easily be deduced as shown in Eq. 24. Another scientific contribution of this study is purely mathematical, as it allows determination of coefficients of the characteristic polynomial of a specific tridiagonal matrix.

[7] Malekinejad, M., Rahgozar, R.: A simple analytic method for computing the natural frequencies and mode shapes of tall buildings, Appl Math Modelling, 36 (2012), pp. 3419-343, https:// doi.org/10.1016/j.apm.2011.10.018

[8] Hochstenbach, M.E.: A Jacobi-Davidson type method for the generalized singular value problem, Linear Algebra and its Applications, 431 (2009), pp. 471-487, https://doi.org/10.1016/j. laa.2009.03.003

[9] Golub, G.H., Van Loan, C.F.: Matrix Computations, $3^{\text {rd }}$ ed., The John Hopkins University Press, Baltimore, Maryland, USA, 1996.

[10] Arnoldi, W.E.: The principle of minimized iteration in the solution of the matrix eigenvalue problem, Quart Appl Math, 9 (1951), pp. 17-29, https://doi.org/10.1090/qam/42792

[11] Saad, Y.: Numerical Methods for Large Eigenvalue Problems, Manchester University Press, Manchester, UK, 1992.

[12] Davidson, E.R.: The iterative calculation of a few of the lowest eigenvalues and corresponding eigenvectors of large realsymmetric matrices, J Comput Phys, 17 (1975), pp. 87-94, https:// doi.org/10.1016/0021-9991(75)90065-0 
[13] Crouzeix, M., Philippe, B., Sadkane, M.: The Davidson method, SIAM J Sci Comput 15 (1994), pp. 62-76, https://doi. org/10.1137/0915004

[14] Morgan, R.B., Scott, D.S.: Preconditioning the Lanczos algorithm for sparse symmetric eigenvalue problems, SIAM J Sci Comput, 14 (1993), pp. 585-593, https://doi.org/10.1137/0914037

[15] Verderame, G.M., lervolino, I., Manfredi, G.: Elastic period of substandard reinforced concrete moment resisting frame buildings, Bull Earth Eng, 8 (2010), pp. 955-972, https:/doi.org/10.1007/ s10518-010-9176-8

[16] Oliveira, C.S., Navarro, M.: Fundamental periods of vibration of RC buildings in Portugal from in-situ experimental and numerical technique, Bull Earth Eng, 8 (2010), pp. 609-642, https://doi. org/10.1007/s10518-009-9162-1

[17] Tong, W., Lingmi, Z., Fah, T.K.: Extraction of real modes and physical matrices from modal testing, Earthq Eng \& Eng Vib, 10 (2011), pp. 219-227, https://doi.org/10.1007/s11803-011-0060-6

[18] Buchholzer, H., Kanzow, C.: Bounds for the extremal eigenvalues of a class of symmetric tridiagonal matrices with applications, Linear Algebra Appl, 436 (2012), pp. 1837-1849, https://doi. org/10.1016/j.laa.2011.10.013
[19] Jia, J., Sogabe, T., El-Mikkawy, M.: Inversion of k-tridiagonal matrices with Toeplitz structure, Comput Math Appl, 65 (2013), pp. 116-125, https://doi.org/10.1016/j.camwa.2012.11.001

[20] Hou-Biao, L., Ting-Zhu, H., Xing-Ping, L., Hong, L.: On the inverses of general tridiagonal matrices, Linear Algebra and its Applications, 433 (2010), pp. 965-983, https://doi.org/10.1016/j. laa.2010.04.042

[21] Akritas, A.G., Strzeboński, A.W., Vigklas, P.S.: Improving the performance of the continued fractions method using new bounds of positive roots, Nonlinear Analysis: Modelling and Control, 13 (2008), pp. 265-279.

[22] Givens, W.: Numerical computation of the characteristic values of a real symmetric matrix, tech. rep., Oak Ridge National Labortary, 1953.

[23] Clough, R.W., Penzien, P.: Dynamics of Structure, McGraw- Hill, New York, USA, 1975.

[24] Trombetti, T., Palermo, M., Silvestri, S., Gasparini, G., Trombetti, T.: Seismic Modal Contribution Factors, Bull Earth Eng, 13 (2015), pp. 1573-1456. 